\title{
Origem e distribuição do nervo isquiático em fetos de suínos (Sus scrofa domesticus - Linnaeus, 1758) da linhagem Pen Ar Lan
}

\author{
Lázaro Antônio dos Santos ${ }^{1 *}$ \\ Frederico Ozanam Carneiro e Silva ${ }^{1}$ \\ Luciana Aparecida Rosa ${ }^{1}$ \\ Lorena Tanús Menezes ${ }^{1}$ \\ Álvaro Carneiro Matoso Nunes Canabrava ${ }^{1}$ \\ Frederico Balbino Lizardo ${ }^{2}$ \\ Daniela Cristina Oliveira Silva ${ }^{2}$ \\ Gilmar da Cunha Sousa ${ }^{2}$ \\ Universidade Federal de Uberlândia \\ ${ }^{1}$ PPG em Ciências Veterinárias, Rua Ceará, s/n, Bloco 2D, sala 03 \\ CEP 38400-902, Uberlândia - MG, Brasil \\ ${ }^{2}$ Instituto de Ciências Biomédicas \\ *Autor para correspondência \\ lazaroseduca@yahoo.com.br
}

Submetido em 24/07/2012

Aceito para publicação em 16/10/2012

\section{Resumo}

Estudou-se a origem e distribuição do nervo isquiático em 31 fetos de suínos da linhagem Pen Ar Lan, sendo 22 machos e nove fêmeas, após ser fixados em solução aquosa de formaldeído a 10\%. Nesses, animais, as vértebras lombares variaram de cinco a sete, com predominância de seis, o que contribuiu para variações na origem do referido nervo. O nervo isquiático originou-se em $80,64 \%$ dos antímeros, do ramo ventral do quinto nervo espinhal lombar (L5); em 96,77\% de L6; em 6,45\% de L7; em 100\% de S1; e em 64,51\% de S2. A composição do referido nervo ocorreu em 45,16\% dos animais pela união de L5, L6, S1 e S2; em 32,25\% de L5, L6 e S1; em 12,90\% de L6, S1 e S2; em 6,45\% de L6, L7 e S1; e em 3,22\% de L5, S1 e S2. Houve simetria na origem do nervo isquiático em todos os espécimes estudados. Esse nervo emitiu ramos para os músculos glúteo superficial, semitendinoso, semimembranoso e bíceps femoral em todos os espécimes, e em menor frequência, para os músculos gêmeos, quadrado femoral, adutores, e glúteos médio, acessório e profundo. Em 74,19\% da amostra, foi observado um ramo comunicante com nervo pudendo.

Palavras-chave: Nervos espinhais; Plexo lombossacral; Sistema nervoso 


\section{Abstract}

Origin and distribution of the sciatic nerve in pig fetuses (Sus scrofa domesticus - Linnaeus, 1758) from the lineage Pen Ar Lan. The origin and distribution of the sciatic nerve was studied in 31 pig fetuses from the lineage Pen Ar Lan, being 22 males and 9 females, after being fixed in a 10\% formaldehyde aqueous solution. In these animals, the lumbar vertebrae ranged from 5 to 7 , with a predominance of 6 , something which contributed to variations in the origin of this nerve. The sciatic nerve originated in $80.64 \%$ of the antimeres from the ventral branch of the fifth lumbar spinal nerve (L5); in $96.77 \%$ of L6; in $6.45 \%$ of L7; in $100 \%$ of S1; and in $64.51 \%$ of S2. The composition of this nerve took place in $45.16 \%$ of the animals due to the union of L5, L6, S1 and S2; in $32.25 \%$ of L5, L6 and S1; in $12.90 \%$ of L6, S1 and S2; in $6.45 \%$ of L6, L7 and S1; and in $3.22 \% \mathrm{~L} 5, \mathrm{~S} 1$ and S2. There was symmetry in the origin of the sciatic nerve in all specimens under study. This nerve sent branches to the superficial gluteal, semitendinosus, semimembranosus and biceps femoris muscles in all specimens, and, in a lesser frequency, to the twins, quadratus femoris, adductors, as well as the middle, accessory, and deep gluteal muscles. In $74.19 \%$ of the sample, a branch communicating to the pudendal nerve was observed.

Key words: Lumbosacral plexus; Nervous system; Spinal nerves

\section{Introdução}

A suinocultura mundial vem se desenvolvendo de maneira acentuada devido aos avanços no melhoramento genético que tem como objetivo a evolução na precocidade dos animais repercutindo assim, de maneira interativa na velocidade de crescimento, na vida produtiva e reprodutiva. Isso tem levado pesquisadores a investigarem, nas linhagens atuais, as variações anatômicas.

A anatomia macroscópica é uma ciência que tem como propósito realizar minuciosa descrição de espécie e/ou comparação entre espécies que apresentem semelhanças morfológicas, e para isso utiliza o método de dissecação, que é o mais direto para a observação das estruturas corpóreas, pois, segundo Kahle et al. (1988), as preparações anatômicas possibilitam a exposição dos órgãos e estruturas permitindo a verificação de sua localização, morfologia e função dentro de um sistema.

O tronco lombossacral compõe a grande parte do plexo lombossacral e continua fora da cavidade pélvica como nervo isquiático, o qual se origina essencialmente por fibras dos ramos ventrais dos últimos nervos lombares e primeiros sacrais (GHOSHAL, 1986a). Emite ramos para a musculatura da região glútea e coxa (LIMA et al., 2008).

Ferraz et al. (2006) descreveram que o termo lombossacral é uma forma genérica de abordar todos os nervos que origina dos plexos lombar e sacral, os quais possuem uma relevante importância clínica-cirúrgica. Diante disso, o tema deste trabalho refere-se ao estudo do nervo isquiático, que se origina do plexo lombossacral.

Contudo, a maioria das informações sobre o nervo isquiático em suínos é obtidas nos tratados de anatomia veterinária que de modo geral referem-se a animais de origem europeia dessa forma, com os cruzamentos de raças e surgimento de novas linhagens deve-se considerar possíveis variações anatômicas.

Portanto, o objetivo deste trabalho foi analisar a origem e distribuição do nervo isquiático em fetos suínos (Sus scrofa domesticus - Linnaeus, 1758) da linhagem Pen Ar Lan.

\section{Material e Métodos}

Foram utilizados 31 fetos de suínos (Sus scrofa domesticus - Linnaeus, 1758) da linhagem Pen Ar Lan, nove fêmeas e 22 machos, oriundos de criatórios da região do Triângulo Mineiro. Nenhum animal foi sacrificado, todos foram originários de aborto natural (natimorto), conduzidos ao laboratório de anatomia veterinária da Universidade Federal de Uberlândia, (UFU, Uberlândia, Minas Gerais, Brasil), para injeção de solução de formaldeído a $10 \%$, as peças foram mantidas submersas na mesma solução por um período mínimo de 48 horas antes do início de dissecação. 
Para proceder à dissecação, foi realizada uma incisão longitudinal na linha mediana ventral, desde a cartilagem xifóide até a borda caudal da sínfise pélvica, a qual foi desarticulada e os órgãos abdominais, pélvicos e tecido adiposo, foram retirados para visualização das vértebras lombares e sacrais e seus respectivos forames intervertebrais, facilitando a individualização dos nervos que compõem o plexo lombossacral, em especial o nervo isquiático.

Para identificação dos ramos do nervo isquiático, foi necessário seccionar transversalmente o terço médio dos músculos bíceps femoral e semitendíneo e rebater cranialmente os músculos glúteos superficial, médio e acessório, no nível do trocânter maior do osso fêmur em cada antímero.

A documentação dos resultados foi realizada a partir de desenhos esquemáticos e fotografias das origens e distribuições dos nervos isquiáticos. A nomenclatura adotada para descrição dos resultados esteve de acordo com o International Committee On Veterinary Gross Anatomical Nomenclature (2005).

$\mathrm{Na}$ análise estatística, em relação às origens e às distribuições dos nervos isquiáticos, optou-se por analisar os dados de forma descritiva em termos de porcentagem simples. Com o intuito de verificar a possível existência de diferenças significativas entre a frequência de ramos dos nervos isquiáticos que se destinaram aos músculos dos antímeros direito e esquerdo, aplicou-se o teste de Wilcoxon.

As diferenças estatísticas entre a frequência de ramos cedidos para os músculos de ambos antímeros em relação ao sexo dos animais foram avaliados pelo teste de Mann-Whitney. O nível de significância foi estabelecido em $5 \%(p<0,05)$ em uma prova bilateral.

\section{Resultados}

Após a avaliação dos 31 fetos de suínos (Sus scrofa domesticus - Linnaeus, 1758) da linhagem Pen Ar Lan, verificou-se variações na quantidade de vértebras lombares, sendo que duas espécimes apresentaram sete vértebras lombares, 28 com seis e um com cinco. Tal fato proporcionou diversificação na origem do nervo isquiático. Diante disso, constatou-se que em 31 fetos as fibras dos ramos ventrais que participaram na formação do nervo isquiático foram compostas por até cinco raízes espinhais, compreendendo os ramos ventrais de L5, L6, L7, S1 e S2 (Figura 1).

As origens dos nervos isquiáticos nos antímeros direito e esquerdo apresentaram simetria em todos os espécimes estudados. Dessa forma, o nervo isquiático originou-se de L5, S1 e S2 em um animal (3,22\%), o qual foi observado cinco vértebras lombares. Em dois animais $(6,45)$ o referido nervo se originou de L6, L7 e S1. Nestes animais constataram-se sete vértebras lombares.

Nos demais espécimes foram constatados seis vértebras lombares e dessa forma, os ramos ventrais de L6, S1 e S2 contribuíram para a formação do nervo isquiático em quatro animais (12,90\%), em dez animais, $(32,25 \%)$, o referido nervo formou-se a partir de L5, L6 e S1 e em 14 espécimes $(45,16 \%)$ dos espécimes ramos de L5, L6, S1 e S2 emitiram fibras para formação do nervo isquiático (Figuras 2, 3 e 4).

Com relação à distribuição, constatou-se que o nervo isquiático ao longo de seu trajeto emitiu ramos para os músculos glúteo superficial (100\%), semitendinoso $(100 \%)$, semimembranoso $(100 \%)$ e bíceps femoral (100\%), em ambos os antímeros. O músculo glúteo médio recebeu ramificações em 33,87\% dos antímeros, 17,74\% exemplares à direita e 16,13\% à esquerda, enquanto os músculos gêmeos receberam fibras deste nervo em $88,70 \%$ dos antímeros, sendo $43,54 \%$ à direita e $43,54 \%$ à esquerda. O músculo quadrado femoral foi inervado pelo referido nervo em $85,48 \%$ dos antímeros, $41,93 \%$ à direita e $43,54 \%$ à esquerda (Figuras 5 e 6 ).

Para os músculos adutores o nervo isquiático emitiu ramos em 37,09\% dos antímeros, sendo $20,96 \%$ exemplares à direita e $16,12 \%$ à esquerda, enquanto os músculos glúteos acessórios receberam ramos em $29,03 \%$ dos antímeros, $14,51 \%$ à direita e $14,51 \%$ à esquerda. Para o músculo glúteo profundo foram direcionadas fibras deste nervo em $25,89 \%$ dos antímeros, 11,29\% à direita e 14,51\% à esquerda. Em 46 antímeros $(74,19 \%)$ dos espécimes, o nervo isquiático emitiu o ramo comunicante do nervo pudendo. 
FIGURA 1: Esquemas (A, B, C, D, e E) representando a composição do nervo isquiático a partir dos ramos ventrais L5, L6, L7, S1 e S2 e suas respectivas percentagens $(3,22 \%, 6,45 \%, 12,90 \%, 32,25 \%$ e $45,16 \%)$.

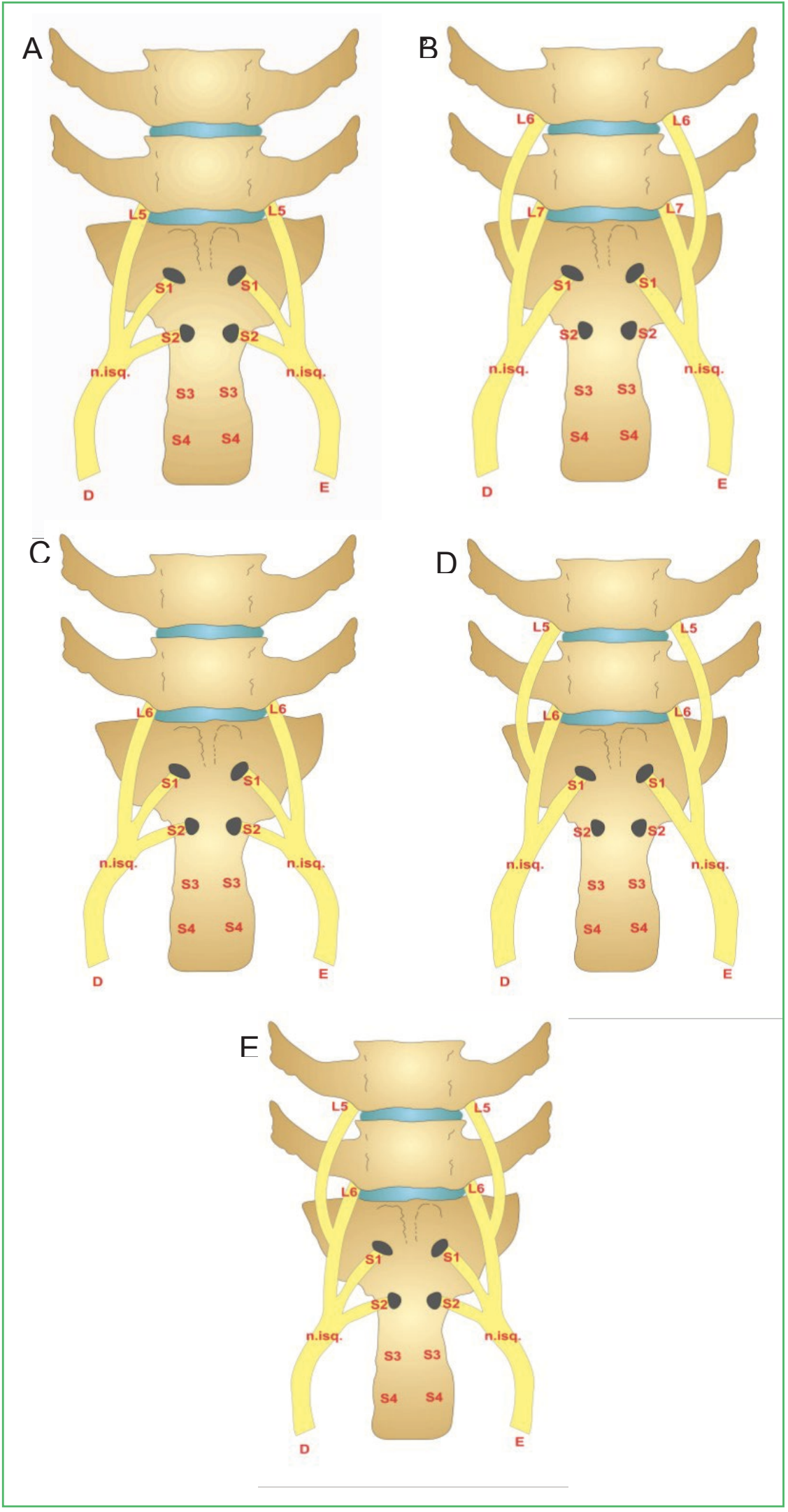


FIGURA 2: Face ventral da região lombar e sacral do coluna vertebral do suino Pen Ar Lan demonstrando a origem do nervo isquiatico (n.isq) a partir dos ramos ventrais de L6, S1 e S2.Incidência de 12,90\%

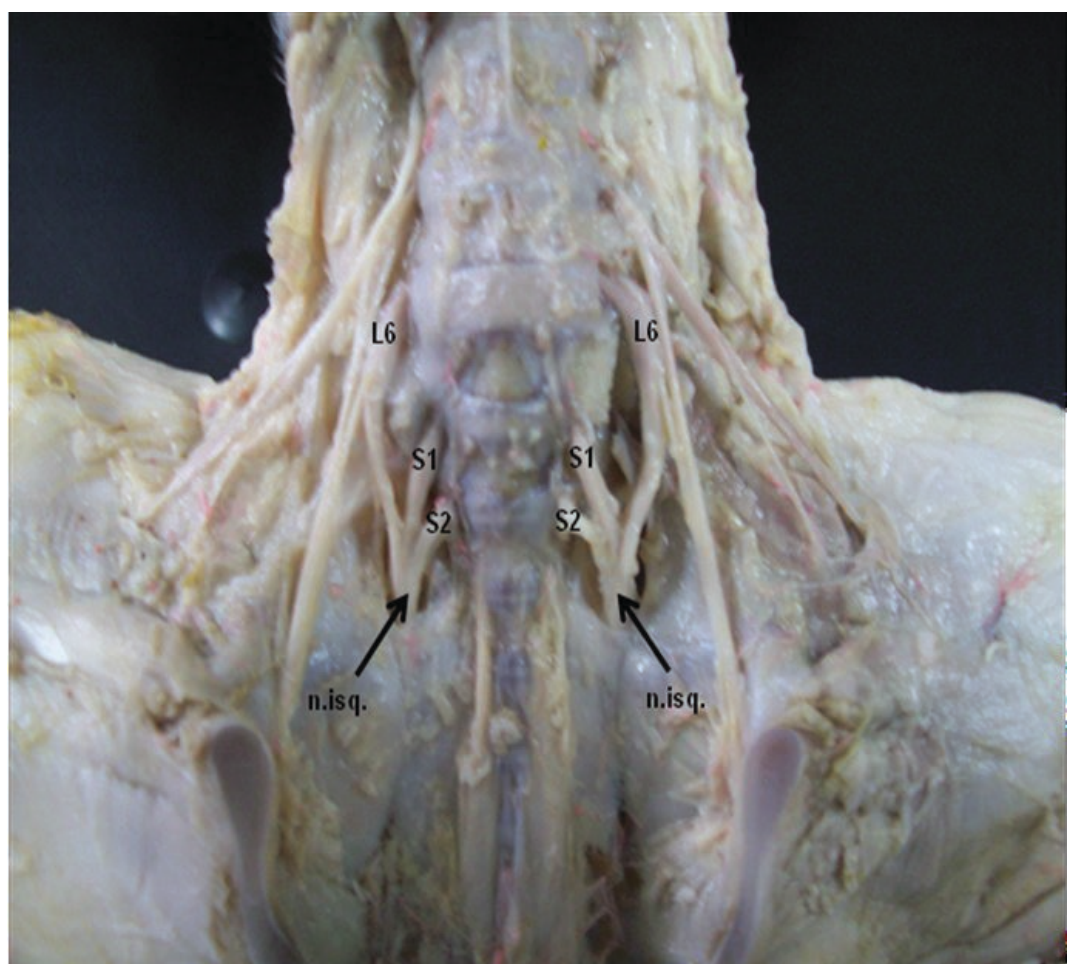

FIGURA 3: Face ventral da região lombar e sacral do coluna vertebral do suino Pen Ar Lan demonstrando a origem do nervo isquiatico (n.isq) a partir dos ramos ventrais de L5, L6 e S1. Incidência de 32,25\%.

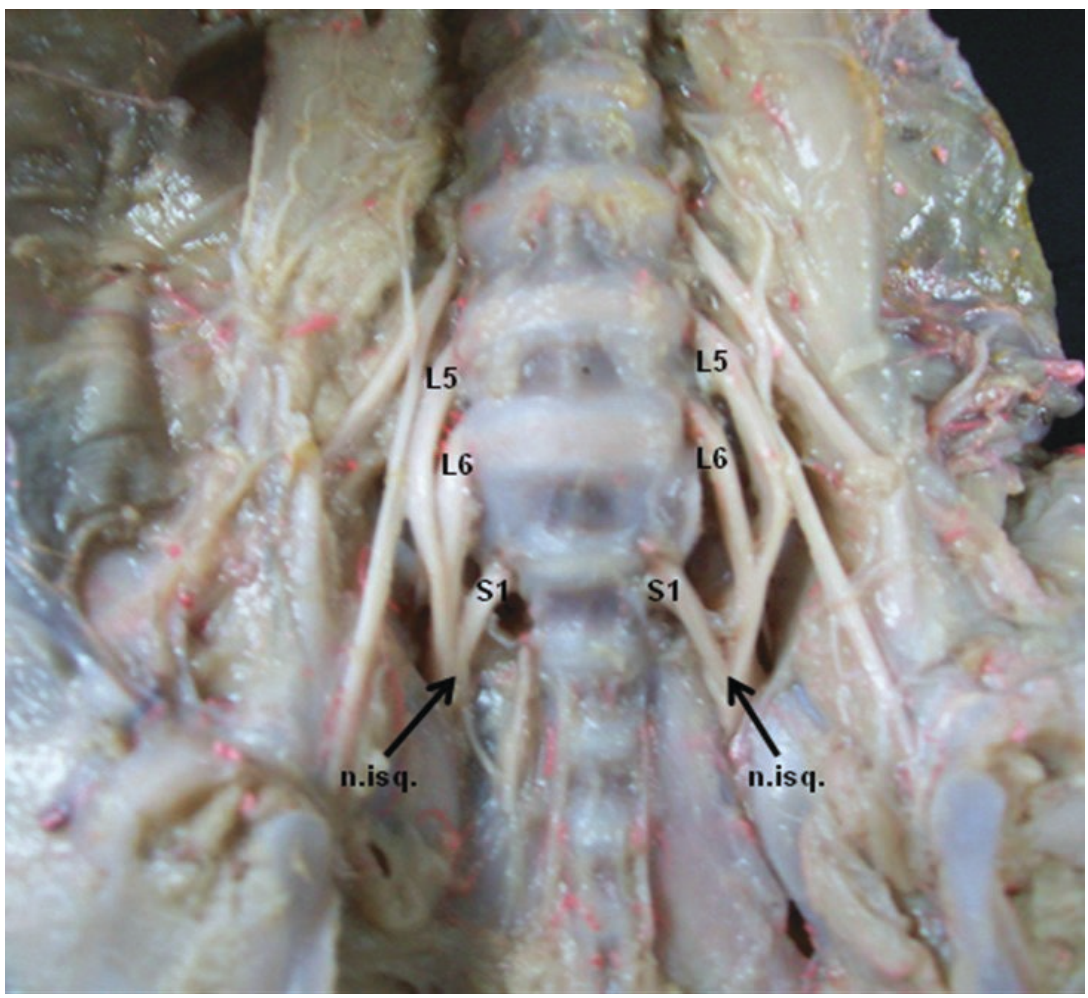


FIGURA 4: Face ventral da região lombar e sacral do coluna vertebral do suino Pen Ar Lan demonstrando a origem do nervo isquiatico (n.isq) a partir dos ramos ventrais de L5, L6, S1 e S2. Incidência de 45,16\%.

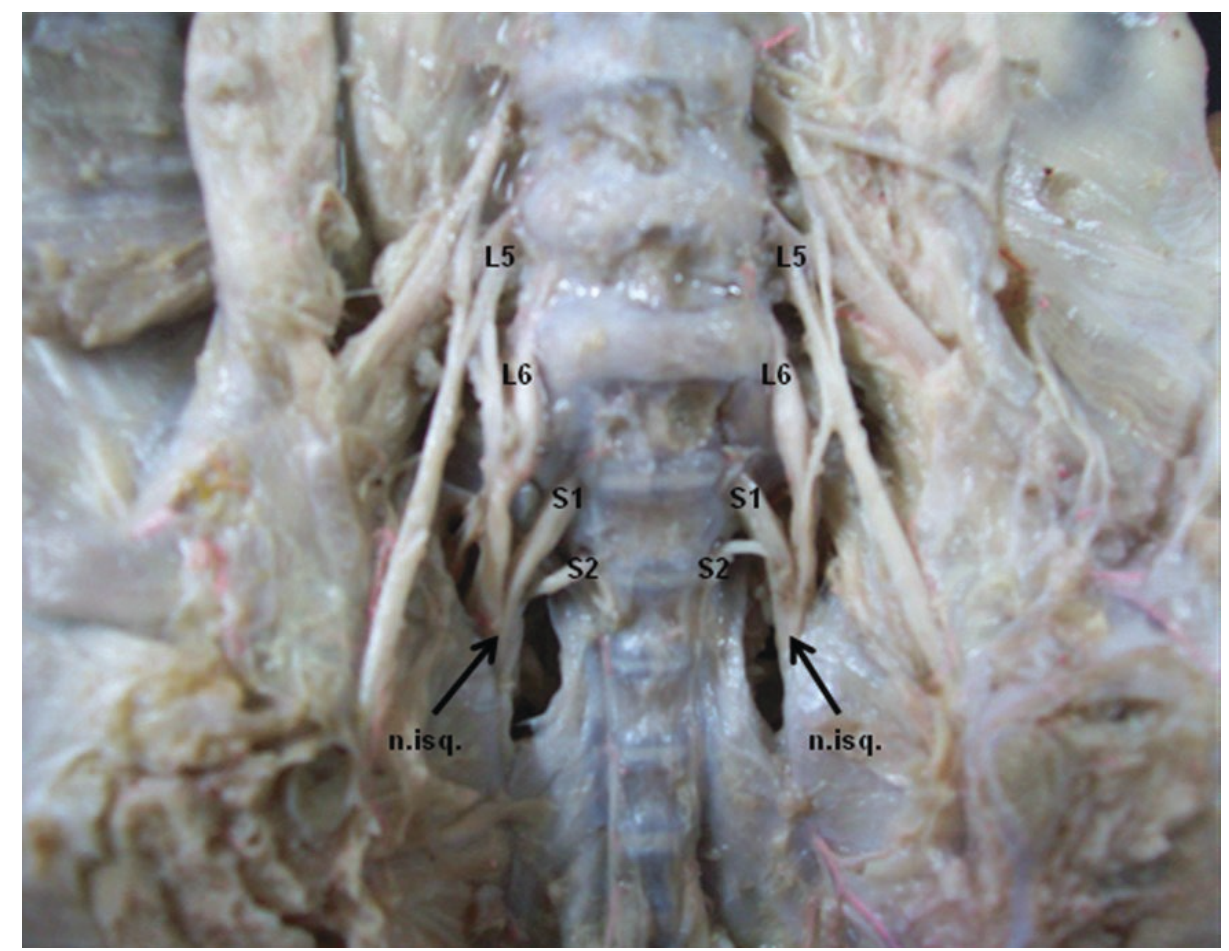

FIGURA 5: Fotografia da face lateral da pelve e coxa do suíno Pen Ar Lan, mostrando o nervo isquiático (n. isq) emitindo ramos para os músculos glúteo médio (glm), glúteo superficial (gls), ramo(*) para os músculos gêmeos (gem), quadrado femoral (qua), bíceps femoral (bfm), semitendinoso (smt), semimembranoso $(\mathrm{smb})$ e a divisão em fibular comum (fib) e tibial (tib).

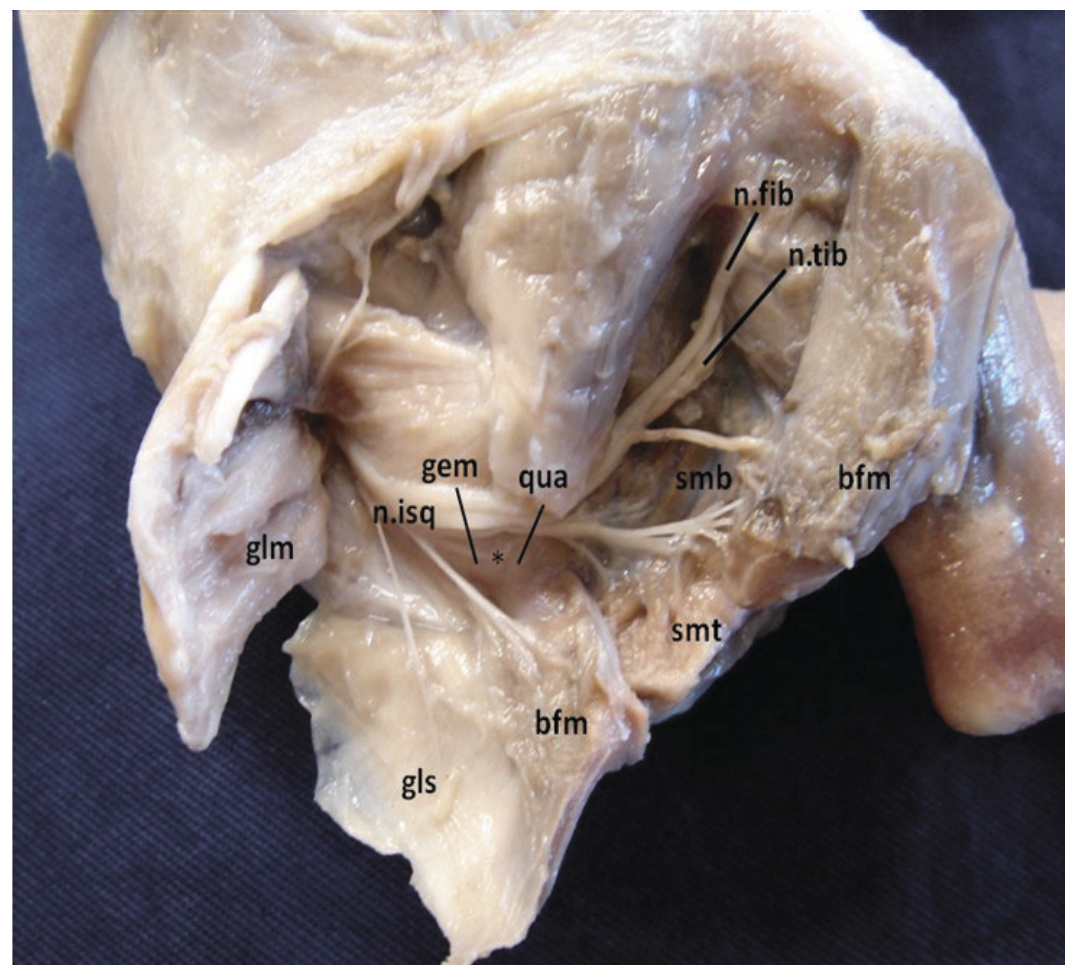


FIGURA 6: Fotografia da face lateral da pelve e coxa do suíno Pen Ar Lan, o nervo isquiático (n.isq) emitindo ramos para os músculos glúteo médio (glm), ramo comunicante para o nervo pudendo (rcp), glúteo superficial (gls), bíceps femoral (bmf), semitendinoso (smt), semimembranoso, (smb) e a divisão em fibular comum (fib) e tibial (tib).

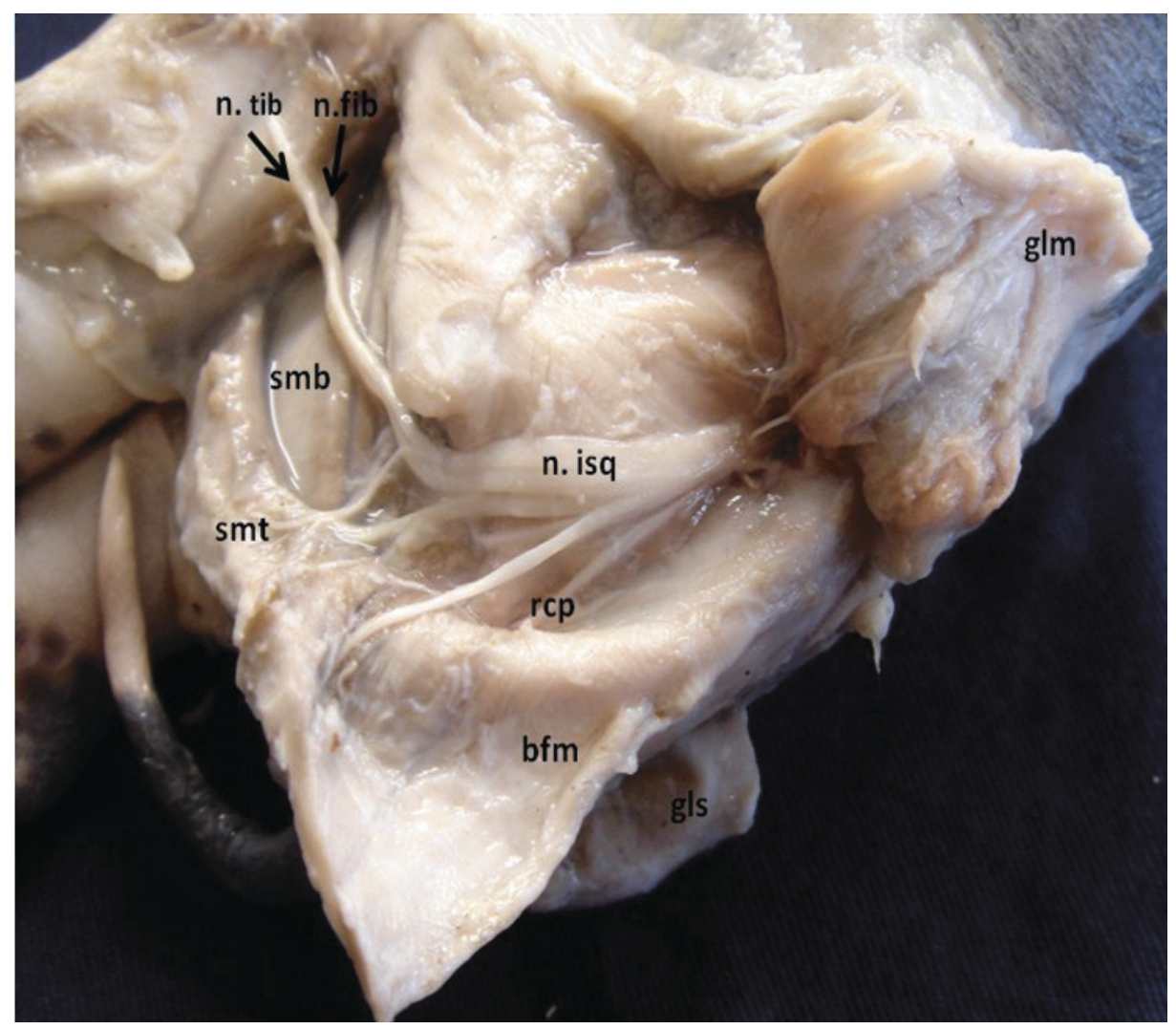

O número de ramos cedido pelo referido nervo para os músculos glúteo superficial, médio e acessório, variaram de um a três, glúteo profundo de um a quatro, para gêmeos, quadrado femoral e adutor um ramo, semimembranoso de um a cinco ramos, semitendinoso de dois a seis e ao bíceps femoral de três a sete.

Através da aplicação do teste de Mann-Whitney, não foram constatadas diferenças significativas ( $p$ $>0,05)$ entre a frequência de ramos emitidos aos músculos de ambos os antímeros em relação ao sexo dos animais estudados. Pela aplicação da prova de Wilcoxon, não se verificou diferenças significativas $(p>0,05)$ entre as frequências de ramos dos nervos isquiáticos emitidos para os músculos nos antímeros direito e esquerdo.

\section{Discussão}

Ferraz et al. (2006) relataram que é muito provável que o nervo isquiático apresente no adulto, origem e sintopia semelhante ao que foi encontrado em fetos de bovinos azebuados, acreditamos que o mesmo fato acontece nos espécimes estudados nesta pesquisa.

Os nervos isquiáticos dos fetos de suínos ( $\mathrm{Sus}$ scrofa domesticus - Linnaeus, 1758) da linhagem Pen Ar Lan apresentaram ampla e variada origem, que ocorreu desde L 5 a S2, um dos fatores determinantes é devido à variação do número de vértebras lombares, fato citado por Pirlot (1976), o qual menciona que as vértebras variam entre espécies ou na mesma espécie. Na presente pesquisa, foram encontradas seis vértebras lombares em 28 animais $(90,32 \%)$ e sete em dois animais $(6,45 \%)$, corroborando com as citações em suínos (SISSON; GROSMAN, 1975; SISSON; HILLMANN, 1986). 
Em 3,22\%, evidenciou-se cinco vértebras lombares em concordância com Ghoshal (1986c).

El-Assy (1966), em primatas, descreveu que na maioria das espécies analisados não foi constatado um nervo isquiático típico, mas foi descrito o nervo fibular comum e nervo tibial que originaram diretamente do plexo lombossacral. Champneys (1975), ao estudar o chimpanzé (Troglodytes niger), mencionou que o referido nervo bifurca-se em nervos fibular comum e tibial ao nível do espaço poplíteo e no macaco (Cynocephalus anubis), isto ocorre logo quando o nervo isquiático deixa a cavidade pélvica. Williams et al. (1995), em humanos, constataram que o ponto de bifurcação varia muito e pode ser dissociado até mesmo em sua origem.

Nos espécimes desta pesquisa todos os animais apresentaram o nervo isquiático envolto por uma bainha de tecido conectivo com sua bifurcação em nervos fibular comum e tibial em nível do terço distal da coxa. Corroborando com as alusões Ghoshal (1986c), em suínos e gatos, Godinho et al. (1987), Dyce et al. (2004), em ruminantes, de Barros (2002), em macacos Cebus apella e Dyce et al. (2004), em equinos.

Constatou-se que as fibras do nervo isquiático originaram a partir dos ramos ventrais de L5, L6, S1 e S2 em 14 espécimes (45,16\%). Fato citado por Bruni e Zimmerl (1977), em ruminantes e, em equinos, Ghoshal (1986c), em suínos, Dyce et al. (2004), em equinos, Lacerda et al. (2006), em mocós, Ferraz et al. (2006), em fetos de bovinos azebuados.

Ghoshal (1986c), em suínos, mencionou que ocasionalmente pode ocorrer uma contribuição dos ramos ventrais de L3 e L4, porém, nesta pesquisa nenhum dos espécimes apresentou fibras, do referido nervo, originárias destes segmentos.

Ghoshal (1986c), em suínos, Campos et al. (2003), Ferraz et al. (2006), em fetos de bovinos azebuado, Lima et al. (2008), em caprinos da raça Saanen, Sousa (2008), em ovinos da raça Morada Nova, relataram que as fibras de S3 contribuíram para formação do nervo isquiático, o que não ocorreu nesta pesquisa.

A composição do referido nervo com fibras originárias de L5, L6 e S1 foi evidenciado em dez animais (32,25\%), corroborando com os relatos de Bruni e Zimmerl (1977), em ruminantes, Lacerda et al. (2006), em mocós, que mencionaram que as fibras do nervo isquiático podem surgir destes seguimentos.

Evidenciou-se em quatro animais (12,90\%), as fibras componentes do nervo isquiático originaram dos ramos ventrais de L6, S1 e S2, o mesmo foi relatado por Sisson e Grossman (1975), em equinos, Schwarze e Schröder (1970), Bruni e Zimmerl (1977), Godinho et al. (1987) e König et al. (2004), em ruminantes, Ghoshal (1986b), em ovinos, Sousa (2008), em ovinos da raça morada, Ghoshal (1986b), em caprinos, Lima et al. (2008), em caprinos da raça Saanen, Campos et al. (2003), Ferraz et al. (2006), em fetos de bovinos azebuados e Santos et al. (2006), em mocós, descreveram que as fibras do referido nervo podem originar-se destes segmentos.

Ghoshal (1986d), em gatos e Guimarães et al. (2005), em gatos domésticos, relataram que os segmentos dos ramos ventrais de L6 e L7 e S1 emitiram fibras para a formação do nervo isquiático. Nesta pesquisa foi observado que em dois animais $(6,45 \%)$, analisados ocorreu a presença de sete vértebras lombares e a mesma origem supracitada.

Contudo, Guimarães et al. (2005), em gatos domésticos e Sousa (2008) em ovinos da raça Morada Nova, relataram que as fibras do referido nervo, em alguns casos derivou-se de L7, S1 e S2, e Molenaar (2004), em seus estudos com cães, relatou que existe uma pequena contribuição do penúltimo nervo lombar enquanto, Ghoshal (1986d), em carnívoros, descreveu, que a segunda contribuição sacral nem sempre está presente. Nesta pesquisa dos animais $(6,45 \%)$ dos exemplares apresentaram sete vértebras lombares e receberam grande contribuição do penúltimo nervo lombar para compor o nervo isquiático, porém não houve contribuição dos ramos ventrais do segundo nervo espinhal sacral.

De acordo com Schwarze e Schröder (1970) e Ghoshal (1986b), em ruminantes, Ferraz et al. (2006), em fetos de bovinos azebuados, as fibras do nervo isquiático derivam essencialmente dos ramos ventrais do ultimo nervo espinhal lombar e primeiro nervo espinhal sacral. 
Nesta pesquisa este fato foi evidenciado em 24 animais $(77,42 \%)$ da amostra.

Nesta pesquisa, foi demonstrada uma baixa incidência da origem do nervo isquiático a partir de L5, S1 e S2, ocorreu em apenas um animal (3,22\%). Discordando com os achados de Barros (2002), em macacos Cebus apella, que mencionou a predominância na formação deste nervo a partir destes ramos.

De acordo com Testut e Latarjet (1979) e Williams et al. (1995), em humanos, o nervo isquiático origina-se de L4, L5, S1 e S2 com grande contribuição de S3, e de acordo com Barros (2002), em macacos Cebus apella, este nervo recebe contribuição do ramos ventrais de L4 a S3 com predominância dos ramos de L5, S1 e S2, nos animais deste experimento não constatou-se a contribuição de L4 e S3 para formação do referido nervo, no entanto, houve a predominância de L5, L6, S1 e S2 .

No tocante à distribuição, constatou-se que o nervo isquiático emite ramos para os músculos semitendinoso, semimembranaso e bíceps femoral em 31 animais (100\%), corroborando com as citações de Schwarze e Schröder (1970), Sisson e Grosmam (1975), Godinho et al. (1987) em ruminantes, Testut e Latarjet (1979) Williams et al. (1995) e Moore e Dalley (2001), em humanos, Ghoshal (1986a), em equinos e suínos, Evans e Delahunta (2001), em cães, Campos et al. (2003) em bovinos azebuados, Santos et al. (2006) em mocós, Lima et al. (2008) em caprinos da raça Sanem e Sousa (2008), em ovinos da raça Morada Nova.

Verificou-se que, nos animais desta pesquisa, o nervo isquiático emitiu ramos para os músculos gêmeos em 55 antímeros $(88,70 \%)$ e para o músculo quadrado femoral em 53 antímeros (85,48\%), corroborando com as alusões em ruminantes (SCHWARZE; SCHRÖDER, 1970; SISSON; GROSMAN, 1975; GODINHO et al., 1987), em cães (SCHWARZE; SCHRÖDER, 1970; GHOSHAL, 1986d; EVANS; DELAHUNTA, 2001), em equinos (SISSON; GROSMAN, 1975; GHOSHAL, 1986a; DYCE et al., 2004), em gatos (GHOSHAL, 1986d; GUIMARÃES et al., 2005) e em caprinos (LIMA et al., 2008).

Ghoshal (1986b), em ruminantes, Campos et al. (2003), em bovinos azebuados, Lima et al. (2008), em caprinos da raça Saanen, Lacerda et al. (2006) e Santos et al. (2006), em mocós, relataram que o nervo isquiático emitiu ramos para os músculos glúteos médio e profundo. Situações observadas, respectivamente, em $21(33,87 \%)$ e $16(25,89 \%)$ dos exemplares da presente investigação. Porém, Guimarães et al. (2005), em gatos domésticos, relataram fibras do nervo isquiático destinada aos músculos piriformes, este fato não foi evidenciado nesta pesquisa.

$\mathrm{O}$ aludido nervo emitiu ramos para o músculo obturador interno em ruminantes (GODINHO et al., 1987), em equinos (SISON; GROSMAN, 1975; GHOSHAL, 1986a; DYCE et al., 2004) e em cães (SCHWARZE; SCHRÖDER, 1970; GHOSHAL, 1986d; EVANS; DELAHUNTA, 2001). Estes achados não estiveram presentes nos espécimes deste estudo.

Ghoshal (1986d) em gatos, Guimarães et al. (2005), em gatos domésticos, Ghoshal (1986d), em cães, mencionaram que o nervo isquiático distribui-se também no músculo abdutor crural, entretanto, nos fetos de suínos da presente pesquisa não foram evidenciados ramos nervosos para tais músculos. De acordo com Ghoshal (1986c) em suínos e gatos e Guimarães et al. (2005), em gatos domésticos, o nervo isquiático emite um ramo comunicante com nervo pudendo. $\mathrm{O}$ que ocorreu em 46 antímeros $(74,19 \%)$ dos espécimes.

Segundo Testut e Latarjet (1979), o nervo isquiático em humanos, distribui-se no músculo adutor magno, enquanto Sisson e Grosman (1975), Godinho et al. (1987), em ruminantes e Campos et al. (2003), em bovinos azebuados, mencionaram que este nervo cede ramos aos músculos adutores. No presente trabalho, foram observadas fibras direcionadas para os músculos adutores em 37,09\% corroborando com as citações dos autores supracitados. Porém, a inervação do músculo quadríceps femoral, relatada por Sousa (2008) em ovinos da raça Morada Nova, não foi evidenciado nos animais desta pesquisa.

De acordo com Ghoshal (1986a), em equinos, os músculos glúteo superficial e acessório recebem fibras dos nervos glúteo cranial e caudal, e nos ruminantes estes músculos recebem fibras do nervo glúteo cranial e nervo isquiático. Nesta pesquisa, o nervo isquiático cedeu 
ramos para os músculos glúteo superficial e acessório em 62 antímeros (100\%) e 18 antímeros $(29,03 \%)$ da amostra, respectivamente.

Em ruminantes o nervo isquiático emite um ramo para o músculo tensor da fáscia lata (GODINHO et al., 1987). Isto não foi evidenciado nesta pesquisa. Contudo, ressaltamos assim, a diversidade de músculos supridos pelo nervo isquiático espécimes abordadas no presente estudo.

A partir dos resultados, foi possível concluir que os nervos isquiáticos em fetos de suínos (Sus scrofa domesticus - Linnaeus, 1758) da linhagem Pen Ar Lan originaram-se de L5 a S2, sendo que, L6 e S1 tiveram maior contribuição. Distribuiram-se nos músculos glúteo superficial, semitendinoso, semimembranoso e bíceps femoral em todos os espécimes estudados, com menor frequência, para os músculos gêmeos, quadrado femoral, adutores e os glúteos médio, acessório e profundo. $\mathrm{Na}$ maioria dos animais $(74,19 \%)$ o nervo isquiático emitiu o ramo comunicante com o nervo pudendo.

Não foram constatadas diferenças significativas entre as frequências de ramos do nervo isquiático emitidos aos músculos de ambos os antímeros e em relação ao sexo dos animais.

\section{Referências}

BARROS, R. A. C. Estudos anatômicos dos plexos lombar, saral e coccígeo do macaco Cebus apella - origem composição e nervos resultantes. 2002. 146 f. Dissertação (Mestrado em Anatomia dos Animais Domésticos) - Universidade de São Paulo, São Paulo. 2002.

BRUNI, A. C.; ZIMMERL, U. Nervi spinali. In: BRUNI, A C.; ZIMMERL, U. (Ed.). Anatomia degli animali domestici. 2. ed. Milano: Casa Editrice Dottor Francesco Vallardi, 1977. p. 535-564.

CAMPOS, D. B.; SILVA, F. O. C.; SEVERINO, R. S.; DRUMMOND, S. S.; LIMA, E. M. M.; BOMBONATO, P. P.; SANTANA, M. I. S. Origem e distribuição dos nervos isquiáticos em fetos de bovinos azebuados. ARS Veterinária, Jaboticabal, v. 19, n. 3, p. 219-223, 2003.

CHAMPNEYS, F. On the muscles and nerves of a Chimpanzee (Troglodytes niger) and Cynocephalus anubis. Journal of Anatomy and Physiology, London, v. 6, n. 1, p. 176-211, 1975.

DYCE, K. M.; SACK, W. O.; WENSING, C. J. G. Tratado de anatomia veterinária. 3. ed. Rio de Janeiro: Elsevier, 2004. 872 p. EVANS, H. E.; DELAHUNTA, A. Abdome, pelve e membro pélvico. In: EVANS, H. E.; DELAHUNTA, A. (Ed.). Guia para a dissecação do cão. 5. ed. Rio de Janeiro: Guanabara Koogan, 2001. p. 163-169.
EL-ASSY, Y. S. Beitrage zur morphologie des peripheren nervensystems der primaten. Gegenbaurs Morphologisches Jahrbuch, Leipzig, [S. 1], p. 476-567, 1966.

FERRAZ, R. H. S.; LOPES, G. R.; MELO, A. P. F.; PRADA, I. L. S. Estudo anatômico da porção intrapélvica do nervo isquiático em fetos de bovinos azebuados. Brazilian Journal of Veterinary Research and Animal Science, São Paulo, v. 43, n. 3, p. 302-308, 2006.

GHOSHAL, N. G. Nervos espinhais. In: GETTY, R. (Ed.). Sisson/ Grossman Anatomia dos animais domésticos. v. 1. 5. ed. Rio de Janeiro: Guanabara Koogan, 1986a. p. 620-642.

GHOSHAL, N. G. Nervos espinhais. In: GETTY, R. (Ed.). Sisson/ Grossman Anatomia dos animais domésticos. v. 1. 5. ed. Rio de Janeiro: Guanabara Koogan, 1986b. p. 1052-1077.

GHOSHAL, N. G. Nervos espinhais. In: GETTY, R. (Ed.). Sisson/ Grossman Anatomia dos animais domésticos. v. 2. 5. ed. Rio de Janeiro: Guanabara Koogan, 1986c. p. 1294-1307.

GHOSHAL, N. G. Nervos espinhais. In: GETTY, R. (Ed.). Sisson/ Grossman Anatomia dos animais domésticos. v. 2. 5. ed. Rio de Janeiro: Guanabara Koogan, 1986d. p. 1595-1617.

GODINHO, H. P.; CARDOSO, F. M.; NASCIMENTO, J. F. Anatomia dos ruminantes domésticos. Belo Horizonte: Universidade Federal de Minas Gerais, 1987. 416 p.

GUIMARÃES, G. C.; MACHADO, M. R. F.; SANTOS, A. L. G.; VIERA, L. C.; SOUZA, A. G.; SILVA, J. M. M.; KAMINISHI, A. P. S. Origem e distribuição do nervo isquiático no gato doméstico (Felis catus domesticus, Linnaeus, 1758). Bioscience Journal, Uberlândia, v. 21, n. 1, p. 189-195, 2005.

INTERNATIONAL COMMITTEE ON VETERINARY GROSS ANATOMICAL NOMENCLATURE. Nomina anatômica veterinária. 5 ed. Hannover: Editorial Committee, 2005. 166 p.

KAHLE, W.; LEONHARDT, H.; PLATZER, W. Atlas de anatomia humana. v. 1. São Paulo: Atheneu, 1988. 416 p.

KONIG, H. E.; LIEBICH, H. G.; CERVENY, C. Sistema Nervoso. In: KONIG, H. E.; LIEBICH, H.; CERVENY, C. (Ed.). Anatomia dos animais domésticos: texto e atlas colorido, órgãos e sistemas. v. 2. Cap. 14. Porto Alegre: Artmed, 2004. p. 203-275.

LACERDA, P. M. O.; MOURA, C. E. B.; MIGLINO, M. A.; OLIVEIRA, M. F.; ALBUQUERQUE, J. F. G. Origem do plexo lombossacral de móco (Kerendo rupestris). Brazilian Journal of Veterinary Research and Animal Science, São Paulo, v. 43, n. 5 p. 620-628, 2006

LIMA, E. M. M.; SILVA, F. O. C.; SEVERINO, R. S.; DRUMMOND, S. S.; CAMPOS, D. B.; SANTANA, M. I. S.; MORAES, D. D. A. Origin and distribution of the ischiatic nerves in goats of the Saanen breed. Ciência Rural, Santa Maria, v. 38, n. 2, p. 372-377, 2008.

MOLENAAR, G. J. Sistema Nervoso. In: DYCE, K. M.; SACK, W. O.; WENSING, C. J. G. (Ed.). Tratado de anatomia veterinária. Cap. 8, Rio de Janeiro: Guanabara Koogan, 2004. p. 256-317.

MOORE, K. L.; DALLEY, A. F. Membro inferior. In: MOORE, K. L.; DALLEY, A. F. (Ed.). Anatomia orientada para a clínica. 4. ed. Cap. 5. Rio de Janeiro: Guanabara Koogan, 2001. p. 445-589.

PIRLOT, P. Morfologia evolutiva de los cordados. Barcelona: Omega, 1976. 966 p. 
SANTOS, R. C.; Albuquerque, J. F. G.; Silva, M. C V.; MOURA, C. E. B.; CHAGAS, R. S. N.; BARBOSA, R. R.; MIGLINO, M. A. Anatomia do nervo isquiático em mócos (Kerodon rupestris WIED, 1820) aplicada à clínica de animais silvestres. Brazilian Journal of Veterinary Research and Animal Science, São Paulo, v. 43, n. 5, p. 647-653, 2006.

SCHWARZE, E.; SCHRÖDER, L. Nervios espinales. In: SCHWARZE, E.; SCHRÖDER, L. (Ed.). Compêndio de anatomia veterinária: sistema nervoso y órganos de los sentidos. Zaragoza: Acríbia, 1970. p. 61-90.

SISSON, S.; GROSSMAN, J. D. Anatomia de los animales domésticos. 4. ed. Barcelona: Salvat, 1975. 952 p.

SISSON, S.; HILLMANN, D. J. Osteologia do suíno. In: GETTY, R. (Ed.). Sisson/Grossman Anatomia dos animais domésticos. v. 2. 5. ed. Rio de Janeiro: Guanabara Koogan, 1986. p.

1139-1173.
SOUSA, E. S. Anatomia do nervo isquiático em ovinos da raça morada nova aplicada a clínica de pequenos ruminantes. 2008. 41 f. Dissertação (Mestrado em Ciência Animal) - Universidade Federal Rural do semi-Àrido, Mossoró. 2008.

TESTUT, L.; LATARJET, A. Anatomia humana. v. 3. 9. ed. Barcelona: Salvat, 1979. 1142 p.

WILLIAMS, P. L.; WARWICK, R.; DYSON, M.; BANNISTER, L. H. Neurologia. In: WILLIAMS, P. L.; WARWICK, R.; DISON, M.; BANNISTER, L. H. (Ed.). Gray Anatomia. 37. ed. Rio de Janeiro: Guanabara Koogan, 1995, p. 809-1173. 